\title{
O ENSINO INVESTIGATIVO COMO FERRAMENTA PARA DESPERTAR INTERESSE EM ALUNOS POR DISCIPLINAS PROFISSIONALIZANTES: RELATO DE EXPERIÊNCIA
}

\author{
Cristiano Luiz Silva Tavares \\ Instituto Federal do Espírito Santo - Campus São Mateus \\ DOI: 10.15628/rbept.2019.7967 \\ Artigo submetido em nov/2018 e aceito em dez/2019
}

\begin{abstract}
RESUMO
Este trabalho descreve uma atividade desenvolvida com uma turma do Ensino Médio integrado ao Curso Técnico em Eletrotécnica. Ao perceber baixo interesse dos estudantes por componentes curriculares, que compõem o eixo de disciplinas profissionalizantes do curso, foi proposta a atividade relatada. Os estudantes foram instigados a investigarem problemas e desenvolverem soluções com base no conteúdo estudado na disciplina Eletrônica Analógica. Pautados na teoria do ensino por investigação, os alunos formaram grupos, investigaram problemas, produziram material experimental, criaram relato científico, apresentaram resultados e avaliaram o processo. A turma, que se mostrava desinteressada pelo curso, especialmente por disciplinas profissionalizantes, após a atividade, demonstrou melhor integração nas disciplinas e motivação para continuar a desenvolver trabalhos científicos.
\end{abstract}

Palavras-Chave: Ensino por projetos. Ensino Médio Profissionalizante. Interdisciplinaridade. Eletrônica Analógica.

\section{TEACHING BY RESEARCH AS A TOOL TO AROUSE INTEREST IN PROFESSIONALIZING DISCIPLINES: EXPERIENCE REPORT}

\begin{abstract}
This paper describes an activity developed in a high school class integrated to the technical course in electrical. When perceiving low interest of the students by the curricular components that compose the axis of professional disciplines of the course was developed the activity reported here. Students were encouraged to investigate problems and develop solutions based on the content studied in the Analog Electronic discipline. Based on the theory of teaching by research, the students formed groups, investigated problems, produced experimental material, created a scientific report, presented their results and evaluated the development. The class that was initially disinterested in the course, especially by professional disciplines, after the activity pointed out better integration of the disciplines and motivation to continue to develop scientific work.
\end{abstract}

Keywords: Teaching by projects. High School Vocational. Interdisciplinarity. Analog Electronics. 


\section{INTRODUÇÃO}

Os Institutos Federais de Educação, Ciência e Tecnologia, conhecidos simplesmente como Institutos Federais, foram criados com a finalidade de ofertar educação profissional e tecnológica, em todos os seus níveis e modalidades, formando e qualificando cidadãos com vistas à atuação profissional nos diversos setores da economia, com ênfase no desenvolvimento socioeconômico local, regional e nacional (BRASIL, 2008).

O Instituto Federal do Espírito Santo - Ifes - possui um campus implementado na cidade de São Mateus, localizada no Norte do Estado. Entre os cursos ofertados por esta unidade se destacam os cursos técnicos em mecânica e em eletrotécnica, ambos integrados ao Ensino Médio. Nesta modalidade de curso, os estudantes possuem disciplinas separadas em dois eixos. Os projetos pedagógicos destes cursos tratam estes dois eixos como:

(i) Base Nacional Comum: composta pelas áreas propostas nos documentos legais: Linguagens, Códigos e suas tecnologias; Ciências Humanas e suas tecnologias; e Ciências da Natureza, Matemática e suas tecnologias, visando possibilitar ao estudante uma base consistente para que ele compreenda o mundo, a influência de suas ações e da própria sociedade e exercite a cidadania.

(ii) Núcleo Profissional: composto por Componentes Curriculares que tratam da formação profissional do Técnico em Eletrotécnica ou Mecânica, visando propiciar aos estudantes o desenvolvimento das competências necessárias ao exercício profissional. (IFES, 2016, p. 17).

O Ifes campus São Mateus é destaque na região na qual está inserido, principalmente, no que se refere à qualidade do ensino desenvolvido com estudantes do Ensino Médio. No ano de 2017, entre as escolas localizadas no município de São Mateus, os estudantes da instituição obtiveram a melhor média no Exame Nacional do Ensino Médio - ENEM (FOLHA, 2018), além de ter sido a escola com maior Índice de Desenvolvimento da Educação Básica - IDEB. A qualidade do ensino gratuito ofertado pelo Ifes campus São Mateus atrai estudantes de cidades do Norte do Estado Espírito Santo, Sul do Estado da Bahia e Nordeste do Estado de Minas Gerais.

Embora o Ifes campus São Mateus oferte cursos de Ensino Médio apenas integrados aos Cursos Técnicos Profissionalizantes se percebe que a maioria dos estudantes ingressantes nesta modalidade de curso busca a qualidade do ensino com interesse na aprovação direta em exames de ingresso aos cursos de Ensino Superior, ou seja, muitos estudantes estão focados apenas em disciplinas do eixo da base nacional comum. Com isto, no Ifes campus São Mateus se percebe desinteresse dos estudantes por 
diversos assuntos abordados em disciplinas, que compõem o núcleo profissional.

Válido destacar que embora os Institutos Federais sejam comumente lembrados pela qualidade de seus cursos profissionalizantes, os mesmos têm em sua lei de criação o objetivo de estimular e apoiar processos educativos, que levem à geração de trabalho e renda e à emancipação do cidadão na perspectiva do desenvolvimento socioeconômico local e regional (BRASIL, 2008). Dessa forma, a função dos Institutos Federais é muito maior que simplesmente formar mão de obra profissional.

Pacheco (2010) destaca que cabe aos Institutos Federais:

[...] uma educação que possibilite ao indivíduo o desenvolvimento de sua capacidade de gerar conhecimentos a partir de uma prática interativa com a realidade. Ao mergulhar em sua própria realidade, esses sujeitos devem extrair e problematizar o conhecido, investigar o não conhecido para poder compreendê-lo e influenciar a trajetória dos destinos de seu lócus. O desenvolvimento local, regional ou nacional não pode prescindir do domínio, da produção e da democratização do conhecimento. Assim, os Institutos revelam-se, espaços privilegiados de aprendizagem, inovação e transferência de tecnologias capazes de gerar mudança na qualidade de vida de milhares de brasileiros. (PACHECO, 2010, p. 18)

Neste contexto, esse trabalho descreve uma atividade desenvolvida como estratégia de ensino, durante o ano de 2017, com uma turma específica do Ifes campus São Mateus do Curso Técnico em Eletrotécnica integrado ao Ensino Médio. A atividade ocorreu durante as aulas da disciplina Eletrônica Analógica, matéria localizada no segundo ano do curso. A turma possuía trinta estudantes regularmente matriculados.

\subsection{Conhecendo um pouco mais a turma envolvida}

Para mais bem conhecer a percepção da turma envolvida sobre o Curso Técnico em Eletrotécnica e, em especial, da aplicabilidade dos conhecimentos técnicos adquiridos na disciplina Eletrônica Analógica foi aplicado um pequeno questionário aos estudantes.

O questionário foi composto por três perguntas. São essas:

I. Você sabia do que se tratava o Curso Técnico em Eletrotécnica antes de ingressar no Ifes?

II. Qual a área de estudos você pretende seguir após terminar seu curso de Ensino Médio? 
III. Você acredita que o conhecimento adquirido na disciplina Eletrônica Analógica possa contribuir na sua vida profissional?

Para a primeira pergunta, os estudantes possuíam três alternativas de resposta: Nada, Pouco ou Muito. O resultado desta pergunta é apresentado na Figura 1.

\section{Você sabia do que se tratava o curso técnico em eletrotécnica antes de ingressar no lfes?}

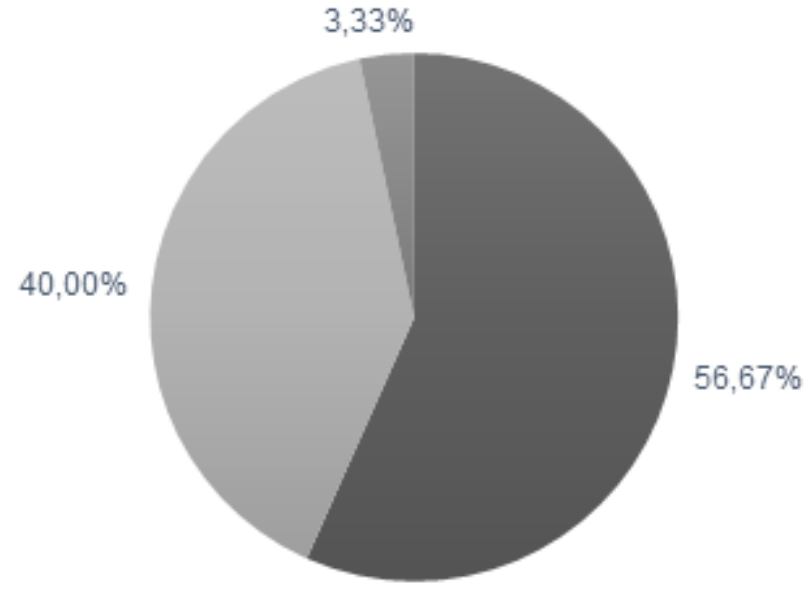

- Nada a Pouco nMuito

Figura 1: Questionário sobre percepção da turma envolvida sobre o Curso Técnico em Eletrotécnica - Pergunta 1.

Percebe-se que mais de metade dos estudantes afirmou que antes de ingressarem no Instituto Federal não conheciam nada do que é estudado em um Curso Técnico em Eletrotécnica. Isto indica que parte representativa dos estudantes não busca o Instituto Federal por uma formação técnica específica. Apenas um estudante afirmou já conhecer muito a temática trabalhada em um Curso Técnico em Eletrotécnica. Infere-se que o desconhecimento prévio pela temática desenvolvida no curso técnico possa contribuir para a desmotivação de alguns estudantes ao se depararem com disciplinas profissionalizantes, distintas daquelas já desenvolvidas no Ensino Fundamental e no eixo de disciplinas da base nacional comum.

A segunda pergunta feita aos estudantes se refere à área de estudos que os mesmos pretendem seguir após finalizar o Curso Técnico em Eletrotécnica integrado ao Ensino Médio. Para melhor apresentação dos resultados, as respostas foram agrupas segundo as subáreas do conhecimento indicadas pela Capes - Coordenação de Aperfeiçoamento de Pessoal de Nível Superior (CAPES, 2017). O resultado é apresentado na Figura 2. 


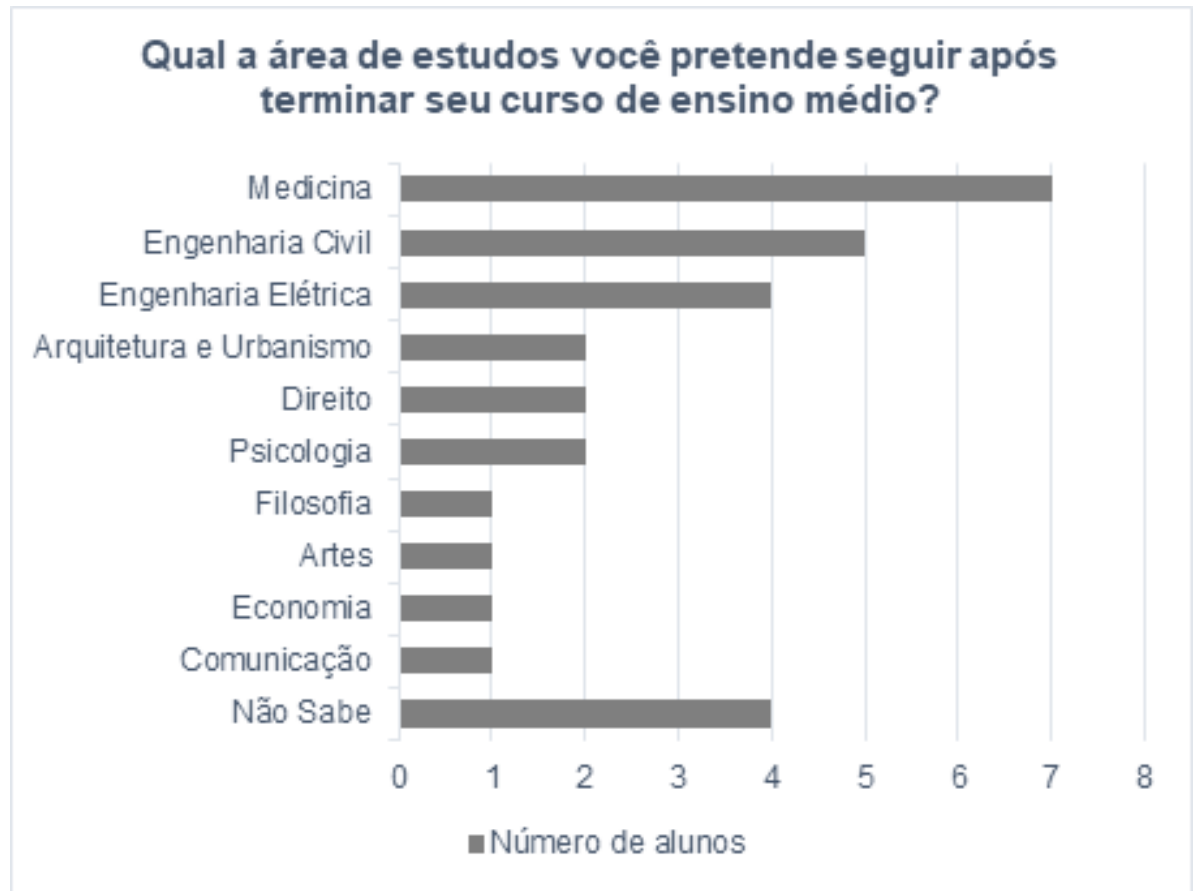

Figura 2: Questionário sobre percepção da turma envolvida sobre o Curso Técnico em Eletrotécnica - Pergunta 2.

Ao analisar este gráfico se percebe que apenas quatro estudantes, o que representa $13,33 \%$ da turma, pretendem seguir seus estudos em Engenharia Elétrica, área do conhecimento a qual o Curso Técnico em Eletrotécnica está inserido. Pode-se inferir que mesmo já inseridos no curso, grande maioria dos estudantes está cursando disciplinas profissionalizantes, que não são de áreas específicas do conhecimento para as profissões que pretendem desempenhar.

Por fim, foi feita a última pergunta do questionário de avalição. Avaliouse a percepção dos estudantes quanto à contribuição da disciplina Eletrônica Analógica perante as profissões que os estudantes pretendem desempenhar. O resultado a esta questão é apresentado na Figura 3. 


\section{Você acredita que o conhecimento adquirido na disciplina em Eletrônica Analógica possa contribuir na sua vida profissional?}

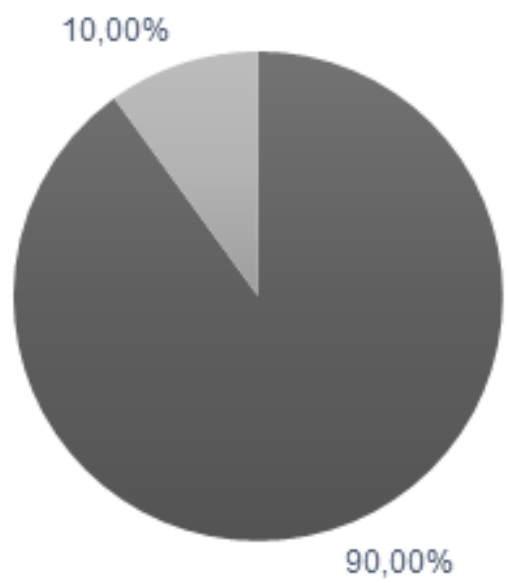

—Sim n Não

Figura 3: Questionário sobre percepção da turma envolvida sobre o Curso Técnico em Eletrotécnica - Pergunta 3.

Nota-se que grande maioria dos estudantes envolvidos acredita que os conteúdos da disciplina Eletrônica Analógica podem contribuir para a vida profissional, mesmo que não continue estudos na área da Engenharia Elétrica. Com este resultado fica claro que, apesar dos estudantes não mostrarem, inicialmente, interesse pelas disciplinas do eixo profissionalizante, estes entendem sua importância.

Sendo assim, o desafio proposto foi elaborar uma atividade em que os estudantes desenvolvessem projetos para aplicação dos conhecimentos já adquiridos na disciplina de Eletrônica Analógica. Estes projetos deveriam solucionar problemas em diversas áreas do conhecimento, conforme interesse dos próprios estudantes. Elencaram-se então alguns objetivos específicos para esta atividade, como:

- Promover a investigação sobre a atuação de Eletrônica Analógica em diversas áreas do conhecimento;

- Promover a interdisciplinaridade de disciplinas do Curso Técnico em Eletrotécnica integrado ao Ensino Médio ofertado pelo Ifes campus São Mateus e;

- Fomentar metodologia científica e interesse por práticas de pesquisa e extensão nos estudantes envolvidos.

O detalhamento dos métodos aplicados nesta atividade para que se atingissem esses objetivos, os resultados obtidos e conclusão serão abordados nas próximas seções. 


\section{METODOLOGIA}

Para que todos os objetivos listados fossem atingidos, a atividade desenvolvida e agora descrita neste texto foi dividida em cinco partes, conforme indica o fluxograma, Figura 4 abaixo:

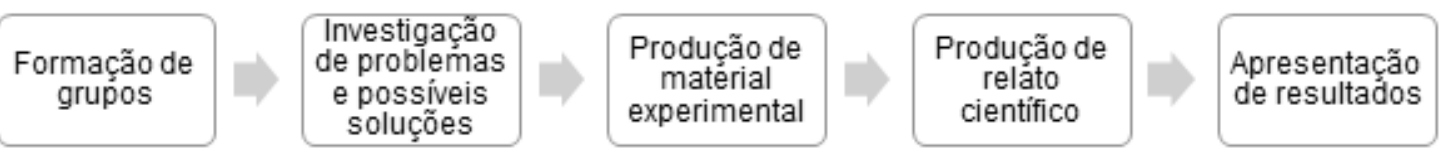

Figura 4: Fluxograma da atividade desenvolvida

Neste texto não se pretende explorar de forma aprofundada cada um dos métodos e técnicas de ensino e aprendizagem abordados durante a atividade desenvolvida. Todavia, para melhor entendimento da proposta descrita neste artigo se apresenta, de forma resumida, os métodos e técnicas empregados, assim como sua contribuição no processo.

\subsection{Trabalho em grupo}

A primeira etapa, formação de grupos, se refere ao agrupar os estudantes, conforme afinidades sociais e por temas a serem desenvolvidos. Conforme lembrado por Haydt (2011, p. 135): "em termos didáticos, os principais objetivos do trabalho em equipe são: facilitar a construção do conhecimento, permitir a troca de ideias e opiniões e possibilitar a prática da cooperação para conseguir um fim comum."

Ainda sobre o trabalho em grupo como um procedimento de ensino e aprendizagem, Bonals (2003) citado por Barbato, Corrêa e Souza (2010, p. 49) destaca que esta técnica:

\footnotetext{
favorece a interação entre os estudantes, incrementando a qualidade das aprendizagens e a aquisição de novos conhecimentos. Além disso, desenvolve as habilidades sociais, possibilitando o diálogo entre os integrantes do grupo, facilitando a comunicação e a inclusão dos mesmos no grupo. (BONALS apud BARBATO, CORRÊA e SOUZA, 2010, p. 49)
}

A escolha por utilizar trabalho em grupo nesta atividade foi justamente para promover $\mathrm{o}$ fortalecimento das relações sociais da turma, além de 
possibilitar o desenvolvimento de trabalhos mais complexos, nos quais a discussão de ideias se faça presente em todo o processo.

\subsection{Investigação de problemas e possíveis soluções}

Esta etapa da atividade foi construída com base em três importantes conceitos da pedagogia: (i) ensino por investigação, (ii) autonomia do estudante pela instigação da criatividade e (iii) interdisciplinaridade.

No ensino por investigação proposto, o estudante se torna protagonista da atividade desde o momento da escolha do tema de seu trabalho científico. Com esta técnica se procura quebrar a repetição de resolução de problemas, em que o professor entrega um problema e o estudante deverá, metodicamente, encontrar a solução. Conforme enuncia Azevedo (2004), no ensino por investigação

[...] o estudante não deve se limitar apenas no trabalho de manipulação ou observação, ela deve também conter características de um trabalho científico: o estudante deve refletir, discutir, explicar, relatar o que dará ao seu trabalho as características de uma investigação científica. (AZEVERO, 2004, p. 21)

Este pensamento corrobora com a promoção da autonomia do estudante pela instigação da criatividade. Freire (2018) anuncia que

[...] o exercício da curiosidade convoca a imaginação, a intuição, as emoções, a capacidade de conjecturar, de comparar, na busca da perfilização do objeto ou do achado de sua razão de ser. (FREIRE, 2018, p. 85)

Para sucesso da atividade proposta se busca a interdisciplinaridade. De acordo com o documento Parâmetros Curriculares Nacionais - Ensino Médio (BRASIL, 2000), na interdisciplinaridade se considera

[...] o fato trivial de que todo conhecimento mantém um diálogo permanente com outros conhecimentos, que pode ser de questionamento, de confirmação, de complementação, de negação, de ampliação, de iluminação de aspectos não distinguidos. (BRASIL, 2000, p. 75).

Em suma, nesta atividade, a autonomia dos estudantes foi promovida quando se propôs a investigação de problemas quaisquer e possíveis 
soluções através de mecanismos estudados na disciplina de Eletrônica Analógica. Aos estudantes se oportunizou exercer a criatividade na produção de seus projetos.

Para promover melhor assimilação do conteúdo estudado em Eletrônica Analógica e gerar melhor empatia a esta disciplina se sugeriu que os estudantes buscassem problemas abordados nas disciplinas, em que o grupo tivesse maior afinidade, ou ainda, dentro daquelas que fossem base para as profissões desejadas.

\subsection{Produção de material experimental e relato científico}

Importante expor que para que a atividade se desenvolvesse com sucesso, os estudantes produziram material experimental e relato científico das possíveis soluções encontradas pelos mesmos.

O intuito da produção de material experimental é garantir a assimilação dos conteúdos já trabalhados na disciplina Eletrônica Analógica. Entende-se por material experimental, neste contexto, a criação de circuitos, de protótipos e de roteiros.

O relato científico foi desenvolvido em forma de um texto escrito nos moldes de um artigo. Ao instigar os estudantes a escreverem em um template de artigo científico se busca gerar familiarização dos mesmos com a escrita científica, além de gerar maior valor a todo trabalho desenvolvido. O template escolhido foi baseado nas normas para trabalhos apresentados em conferências do Instituto de Engenheiros Eletricistas e Eletrônicos - Institute of Electrical and Electronic Engineers (IEEE, 2018). Este órgão é referência para eventos e periódicos na área de Engenharia Elétrica.

\subsection{Apresentação de resultados}

Após todo o processo já descrito, os estudantes tiveram a oportunidade de apresentar e compartilhar seus trabalhos com os demais colegas de sala de aula. Foram convidados professores de diversas áreas para participarem deste momento. Estes professores foram essenciais para auxiliar os alunos nas soluções interdisciplinares encontradas.

Todos os presentes, no momento das apresentações, puderam avaliar cada um dos trabalhos, inclusive os estudantes.

Para promover o pensamento crítico dos estudantes sobre os objetivos da atividade, foi desenvolvida uma ficha de avaliação dos estudantes. Estes deveriam pontuar cinco afirmações em uma escala de 1 a 4 , em que: 1. 
Discordo completamente; 2. Discordo em partes; 3. Concordo em parte e 4. Concordo completamente. As cinco afirmações pontuadas foram:

I. É perceptível o uso dos conhecimentos adquiridos na disciplina Eletrônica Analógica no trabalho!

II. É perceptível a integração da disciplina Eletrônica Analógica com outra disciplina do curso!

III.O grupo soube apresentar com clareza e segurança o trabalho desenvolvido!

IV.Todos os integrantes do grupo participaram e mostraram segurança no trabalho desenvolvido!

V. O nível do trabalho é compatível ou superior com o conhecimento desenvolvido em sala de aula!

\section{RESULTADOS E DISCUSSÕES}

A turma que desenvolveu esta atividade gerou seis trabalhos em grupos. Estes trabalhos foram nomeados como:

- Grupo 1. Processos de Corrosão Utilizando Percloreto de Ferro III

- Grupo 2. Estação de Recarga de Celular com Energia Solar

- Grupo 3. Alimentador Temporizado de Animais

- Grupo 4. Amplificador de Áudio

- Grupo 5. Irrigação Automatizada de Jardins

- Grupo 6. As Principais Rotas das Grandes Navegações

Percebe-se pelo nome dos próprios trabalhos a variedade de assuntos desenvolvidos. Esta variedade mostra a interdisciplinaridade ocorrida durante o desenvolvimento da atividade.

Notou-se, ainda, o grande envolvimento dos estudantes na realização da atividade. Estudantes que demonstravam baixo rendimento na disciplina mostraram maior motivação para pesquisar e trabalhar com assuntos relativos à desejada profissão.

Destaque para os grupos que criaram soluções implementadas na própria escola, como o grupo Processos de Corrosão Utilizando Percloreto de Ferro III e o grupo Estação de Recarga de Celular com Energia Solar. No primeiro, resolveu-se um problema recorrente na escola sobre como descartar resíduo proveniente da confecção de placas de circuito impresso, feita pelos alunos do Curso Técnico em Eletrotécnica. Já o segundo projeto, criou caixas onde a comunidade acadêmica pode recarregar seus celulares utilizando energia solar. Esta atitude gera economia ao campus, além de 
diminuir a quantidade de celulares utilizados em sala de aula, já que estes estão sendo carregados nas estações no jardim da escola.

Os grupos 3, 4 e 5 foram trabalhos propostos pelos estudantes a partir de uma demanda externa a escola. O Alimentador Temporizado de Animais é um dispositivo que detecta a necessidade de fornecer ração a animais domésticos quando seus donos estão ausentes po longo período de tempo, como em viagens por exemplo. O grupo de Amplificador de Áudio foi capaz de criar um amplificador potente e de baixo custo se comparado as caixas de som encontradas no mercado. O amplificador foi sucesso entre os estudantes de toda escola. Já o grupo de Irrigação Automatizada de Jardins criou um dispositivo capaz de medir a umidade do solo e luminosidade do dia e decidir quando irrigar um gramado.

O grupo que desenvolveu o trabalho intitulado: As Principais Rotas das Grandes Navegações doou seu trabalho para uma escola de Ensino Fundamental. Em suma, este grupo mostrou de madeira lúdica o caminho percorrido por diversos navegadores, utilizando lâmpadas acionadas por circuitos eletrônicos. Este trabalho é apresentado na imagem abaixo.

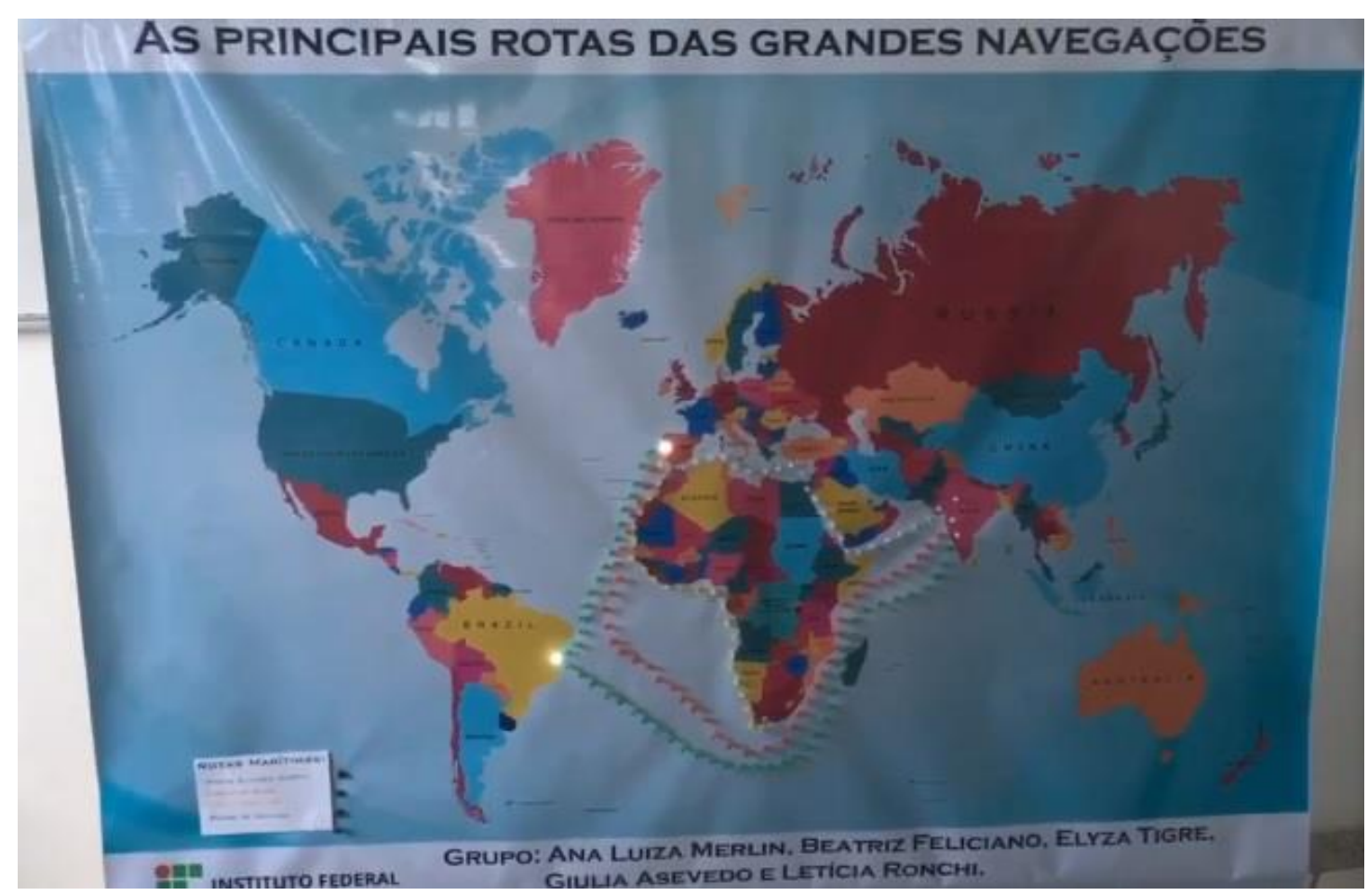

Figura 5: Trabalho desenvolvido pelos alunos: As principais rotas das grandes navegações

Para avaliar a atividade desenvolvida pelos estudantes, ao final de todo processo foi feita uma roda de conversa com todos os envolvidos. Os estudantes pontuaram o desafio e o prazer em desenvolver as atividades. Em suma, foi apontada a dificuldade inicial em se trabalhar de um projeto no qual, incialmente, não havia um roteiro a ser seguido e a proposta deveria vir dos 
próprios estudantes. Vencido este desafio de encontrar um tema, o trabalho se fez mais prazeroso.

Os estudantes apontaram, ainda, a importância da necessidade de interligar as disciplinas estudadas, ou seja, promover a interdisciplinaridade. Apontaram ainda que os assuntos estudados e já cobrados em provas se tornaram mais claros e, principalmente, se mostraram mais úteis no dia a dia.

Por fim, os estudantes informaram que se sentiram mais integrados ao Curso Técnico em Eletrotécnica, com maior valorização das disciplinas do núcleo profissional. Apontaram, ainda, o interesse em continuar os trabalhos, mesmo após o término da disciplina Eletrônica Analógica, como no caso do Processos de Corrosão Utilizando Percloreto de Ferro III, que transformou o trabalho em um projeto de iniciação científica.

\section{CONSIDERAÇÔES FINAIS}

Após todo o processo da atividade descrita se pode concluir que o ensino por investigação atrelado com a interdisciplinaridade pode ser uma ferramenta de grande valia na promoção da autonomia do estudante, principalmente, no que se refere ao desenvolvimento de projetos de disciplinas do núcleo profissional de um Curso Técnico integrado ao Ensino Médio.

O estudo descrito neste artigo se refere a uma turma específica do Curso Técnico em Eletrotécnica integrado ao Ensino Médio do Ifes campus São Mateus. Esta turma que, inicialmente, se mostrava desinteressada pelo curso, especialmente por disciplinas do núcleo profissional, após a atividade, demonstrou melhor integração das disciplinas e motivação para desenvolver trabalhos científicos.

\section{REFERÊNCIAS}

AZEVERO, M. C. P. S. D. Ensino por investigação: problematizando as atividades em sala de aula. In: CARVALHO, A. M. P. Ensino de Ciências: unindo a pesquisa a prática. São Paulo: Pioneira Thomson Learning, 2004. p. 19-33.

BARBATO, G. R.; CORRÊA, A. K.; SOUZA, M. C. B. D. M. E. Aprender em grupo: experiência de estudantes de enfermagem e implicações para a formação profissional. Escola Anna Nery, Rio de Janeiro, Jan./Mar. 2010. 48-55. 
BRASIL. Parâmetros Curriculares Nacionais Ensino Médio: bases legais, Brasília, 2000.

BRASIL. Lei № 11.892, de 29 de dezembro de 2008. Institui a Rede Federal de Educação Profissional, Científica e Tecnológica, cria os Institutos Federais de Educação, Ciência e Tecnologia, e dá outras providências. Diário Oficial da União, Brasília, 30 dezembro 2008.

CAPES - Fundação Coordenação de Aperfeiçoamento de Pessoal de Nível Superior. Site da Fundação Coordenação de Aperfeiçoamento de Pessoal de Nível Superior, Brasília, 31 jan. 2017. Disponivel em:

<https://capes.gov.br/images/documentos/documentos_diversos_2017/Tabela AreasConhecimento_072012_atualizada_2017_v2.pdf >. Acesso em: 28 out. 2019.

FOLHA. Veja o desempenho da sua escola no Enem 2017. Site da Folha de São Paulo, 2018. Disponivel em:

<https://www1.folha.uol.com.br/educacao/2018/06/veja-o-desempenho-dasua-escola-no-enem-2017.shtml>. Acesso em: 16 nov. 2018.

FREIRE, P. Pedagogia da autonomia: saberes necessários à prática educativa. 56a . ed. São Paulo: Paz e Terra, 2018.

HAYDT, R. C. C. Curso de Didática Geral. 1a․ ed. São Paulo: Ática, 2011.

IEEE - Institute of Electrical and Electronic Engineers. Manuscript Templates for Conference Proceedings, 2018. Disponivel em:

<https://www.ieee.org/conferences/publishing/templates.html>. Acesso em: 28 out. 2019.

IFES campus São Mateus - Instituto Federal do Espírito Santo campus São Mateus. Projeto Pedagógico do Curso Técnico em Eletrotécnica Integrado ao Ensino Médio, São Mateus, 2016.

PACHECO, E. M. Os Institutos Federais: uma revolução na educação profissional e tecnológica. 1a. ed. Natal: Editora do IFRN, 2010. 
ISSN - 2447-1801

REVISTABRASILEIRA

DA EDUCACÃ̃O PROFISSIONAL E TECNOLÓGICA

Vol. 2 (2019) 